Leading Article

\title{
The role of tracheostomy in the adult intensive care unit
}

\author{
E.R. Grover and D.J. Bihari \\ Guy's Hospital, St Thomas Street, London SE1 9RT, UK
}

Intubation of the human trachea has been practised since ancient times. There are reports of the Egyptians using tracheostomy for acute upper airway obstruction 3,500 years ago ${ }^{1}$ and its use was described in Ancient Greece in the year 100 BC by Asclepiades. ${ }^{2}$ A variety of methods to secure the airway have since been devised. Orotracheal tubes were first used during anaesthesia by MacEwan in 1878 , and the idea was further developed by Magill and Rowbotham in the 1920s. Transglottic tracheal intubation became popular in anaesthetic practice with the advent of intraoperative muscle paralysis, after 'curarization' was described by Griffiths and Johnson in 1942. The contemporary technique of surgical tracheostomy was first described in 1909 by Jackson. ${ }^{3}$ Despite the life-saving value of intubation in the management of the critically ill, much controversy still surrounds the indications for, and complications associated with, the alternative methods employed for securing the airway. The paper by Gunawardana published in this journal adds further fuel to the raging fire of debate concerning these issues. ${ }^{4}$

The indications for tracheal intubation during intensive care, are well established. It provides security against airway obstruction and aspiration of pharyngeal content in the obtunded/unconscious patient, and enables ventilatory support in the presence of respiratory failure. Tracheal access also allows regular clearance of broncho-pulmonary secretions by suctioning, usually combined with formal physiotherapy. The route used, timing and subsequent management of tracheal cannulation, however, remain issues of contention.

Most critically ill patients requiring intubation, are initially managed with a transglottic, cuffed, tracheal tube. This may be introduced via the nose or mouth and each route has its advocates. Nasal intubation allows more stable fixation of the tube (the prime reason for its frequent use in children),

Correspondence: $\quad$ D.J. $\quad$ Bihari, M.A., M.R.C.P., Director-Intensive Care Services, Guy's Hospital, St Thomas Street, London SE1 9RT, UK.

Received: 21 November 1991 and is often claimed to be better tolerated. ${ }^{5}$ There is little objective evidence to support the latter statement, which seems unlikely, since both options require transit through the glottis, the most sensitive region of the respiratory tract. Siting of a nasotracheal tube has been shown to be associated with prolonged insertion time, increased risk of hypoxia and greater haemodynamic instability. ${ }^{6}$ It has also been related to sinusitis, otitis media and ulceration of the nasal mucosa. Because of the narrow nasal orifice the maximum tube diameter is limited. This combined with its additional length, inevitably results in higher resistance to air flow and increased respiratory work during spontaneous ventilation. These problems are sufficient to contraindicate routine nasal intubation within our unit.

Oral intubation also has related problems. The tube is not easy to secure firmly, and the agitated patient may bite it, occluding the lumen. Oral hygiene is difficult to perform adequately and angular stomatitis may occur, usually related to the securing tapes. These difficulties can usually be prevented with good nursing care and in our opinion, this is the route of choice for perioperative and short-term intubation (see Figures 1 and 2).

There is undoubtedly a range of glottic pathology that can be related to the presence of an endotracheal tube. Laryngeal trauma may be caused during intubation, resulting in minor mucosal damage, vocal fold injury, or even arytenoid dislocation. ${ }^{7}$ Once positioned, pressure from and movement of the tube may provoke glottic ulceration, granuloma formation and ultimately laryngotracheal stenosis, reported to occur in $12 \%$ of patients after 11 days. ${ }^{8}$ In an attempt to avoid these serious complications, it is accepted practice that patients needing prolonged intubation (i.e. more than 7-10 days) should have a sub-glottic tracheal tube sited via a tracheostomy. ${ }^{9}$ This is also said to improve patient comfort and reduce the need for sedation during the weaning period, whilst oral hygiene and enteral nutrition can be better provided. It is commonly stated that tracheostomy reduces both respiratory dead space ${ }^{10}$ and the work of breathing', although these benefits are 


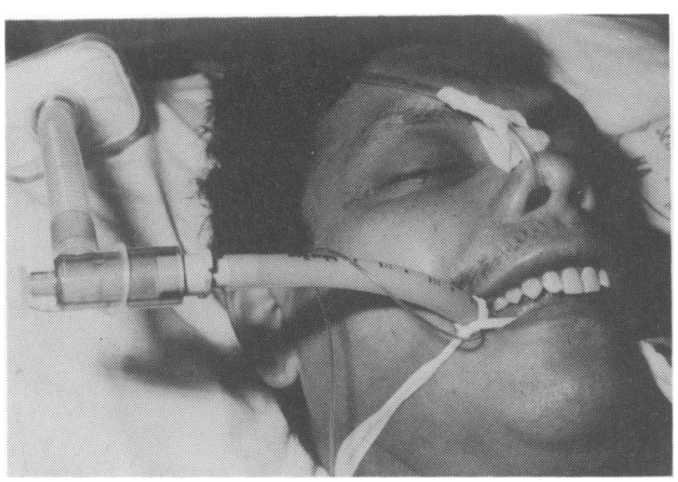

Figure 1 A patient intubated with an un-cut orotracheal tube, poorly secured and with inadequate support of the ventilator hoses.

probably marginal in the intubated patient.

Modern open surgical tracheostomy is still based on Jackson's classic paper, ${ }^{3}$ and is performed at the level of the second and third tracheal rings. Various types of tracheal incision have been recommended: a Bjork (inverted ' $U$ ') tracheal flap; ${ }^{11}$ an excised window; ${ }^{12}$ a vertical or transverse split. ${ }^{13}$ They have all been claimed to limit the risk of tracheal stenosis, whilst the flap technique was intended to prevent anterior misplacement of the tube (this technique has since been discredited).

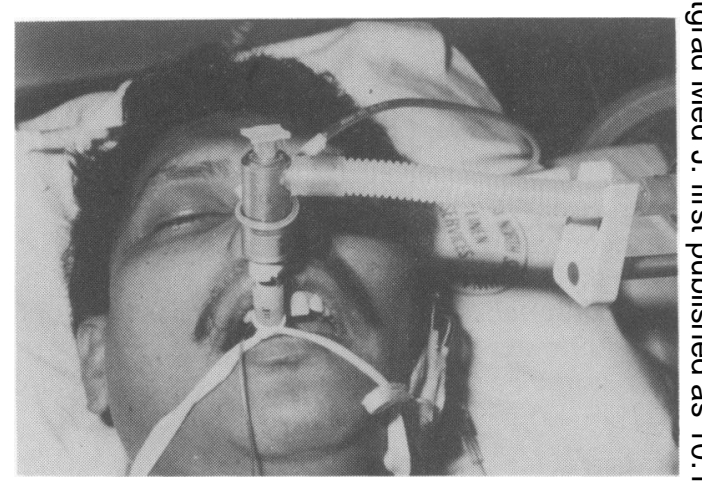

Figure 2 The same patient with the tube correctly fixed and a ventilator gantry supporting the hoses.

Percutaneous tracheostomy was first described $े$ by Toye and Weinstein ${ }^{14}$ but it failed to attract significant support. A revised Seldinger guide-wire $\vec{\omega}$ technique presented by Ciaglia, ${ }^{15}$ using a series of $O$ tracheal dilators, has provoked new interest. Several clinical studies have now been reported, ${ }^{16-19}$ airway access being obtained above the first, second or third tracheal ring. Initial evidence suggests that complication rates compare favouf ably with open surgery. ${ }^{20}$ It can be easily performe on the ward, using local anaesthesia, thus avoiding

Table I Methods of prolonged intubation-advantages and problems

Route Advantages Hazards/complications

All

Airway access and security

Prevention of aspiration

Transglottic

Avoids risks of tracheostomy

Nasotracheal

Orotracheal

Tube fixation/immobilization Access for oral hygiene

Lowest incidence of serious sequelae

Transtracheal
Patient comfort/minimal sedation Speech during spontaneous ventilation Patient can usually swallow (reduced dead-space/respiratory work)
Pulmonary infection

Tracheal ulceration/granulomata/stenosis

Tracheomalacia

Tracheal perforation

Patient discomfort/increased sedation/aphonia

Enteral/parenteral nutrition required

Laryngeal injury:

vocal fold ulceration/granulomata/polyps sicatrix/web formation laryngeal stenosis/laryngomalacia chronic voice change

Increased airflow resistance

Naris/nasal mucosal ulceration

Sinusitis/(otitis media)

Oral hygiene compromised

Angular stomatitis

Subglottic/tracheal stenosis

Tracheo-innominate artery/vein fistula

Tracheo-oesophageal fistula

Stomal erosion/bleeding/infection

Stomal epithelialization

Surgical emphysema/mediastinitis 
the hazards of patient transfer to the operating theatre, for example, loss of positive end expiratory pressure, inadequate monitoring and the risks of disconnection. Contraindications include obesity, goitre, paediatric patients and acute upper airway obstruction. ${ }^{15}$

Cricothyroidostomy (siting of a tracheal tube through the cricothyroid membrane), was condemned by Jackson in $1921^{21}$ as a potent cause of sub-glottic stenosis. This was challenged by Brantigan and Grow, ${ }^{22}$ who published a retrospective study of 655 patients. They subsequently presented data ${ }^{23}$ suggesting that stenosis is a significant risk in any patient with pre-existing laryngeal pathology, including prior trans-glottic intubation. There is probably no place for this procedure in routine practice.

Minitracheostomy was introduced in 1984 by Matthews and Hopkinson. ${ }^{24} \mathrm{~A}$ small bore PVC tube is placed in the trachea via a transverse puncture wound, made in the cricothyroid membrane. This is easy to perform and has a valuable role in the treatment of sputum retention. It preserves glottic integrity and therefore speech. In some cases, especially in combination with continuous positive airway pressure (CPAP) administered by facemask, it may prevent formal intubation/ventilation whilst also being a useful aid to weaning from respiratory support. There have been several case reports of complications using this device, including stomal haemorrhage, ${ }^{25}$ oesophagea ${ }^{26}$ and pleura ${ }^{27}$ misplacement. It has been suggested that these may be reduced by using a guide-wire during insertion. ${ }^{28}$ The procedure should be avoided in patients with a bleeding diathesis, and those unable to protect their airway, that is, those who need intubation with a cuffed tube. ${ }^{29}$

Intubation via any route is associated with many potentially serious complications (see Table I) ${ }^{30,31}$ The most severe of these are sepsis, haemorrhage and laryngo-tracheal stenosis. Their incidence are therefore commonly quoted by studies investigating the relative merits of prolonged translaryngeal intubation compared with early tracheostomy. It is clear that potential mucosal damage due to pressure necrosis occurs at any site of tube-tissue contact. ${ }^{32}$ Previously this was most apparent in relation to the sealing cuff. With the exclusive use of thin walled, large diameter, high residual volume cuffs ${ }^{33}$ in the critically ill, and care to prevent cuff inflation pressure exceeding 30 $\mathrm{mmHg},{ }^{34}$ this cause of stenosis should now be avoidable. Problems remain with trans-glottic tubes where they impact against the posterior endolarynx. It is evident that damage increases with duration of intubation and movement of the tube, a problem in the restless patient. ${ }^{8}$ Female insulin-dependent diabetics seem to be particularly at risk, and should be considered for early tracheostomy. ${ }^{32}$

Significant problems due to tissue trauma are also related to trans-tracheal intubation. Subglottic stenosis secondary to 'high' tracheostomy (immediately above or below the cricoid ring), has long been described, ${ }^{21}$ and was further witnessed during the evaluation of cricothyroidostomy ${ }^{35}$ The incidence of tracheal stenosis clearly recedes as the stoma is sited more distant from the larynx, this being the narrowest and most vulnerable region in the upper respiratory tract. In contrast, the lower the tracheostomy, the greater the risk of tracheoinnominate artery fistula formation. ${ }^{36}$ This dramatic complication is reported to occur in $0.4-0.6 \%$ of tracheostomies, ${ }^{37,38}$ although these estimates are from retrospective surveys. Some minor tracheal bleeding is first observed in $30 \%$ of cases, ${ }^{38}$ and should always be carefully investigated with a view to preventative surgery. Attempted first aid measures to control the haemorrhage should include hyper-inflation of the cuff and retrosternal digital pressure via an incision in the suprasternal notch ${ }^{39}$ (see Figure 3). Emergency surgery requires median sternotomy and ligation/excision of the eroded artery. With an associated $75 \%$ mortality, ${ }^{38}$ every effort should be made to prevent this disaster. Consequently routine tracheostomy, whether surgical or percutaneous, should never be sited below the third tracheal ring.

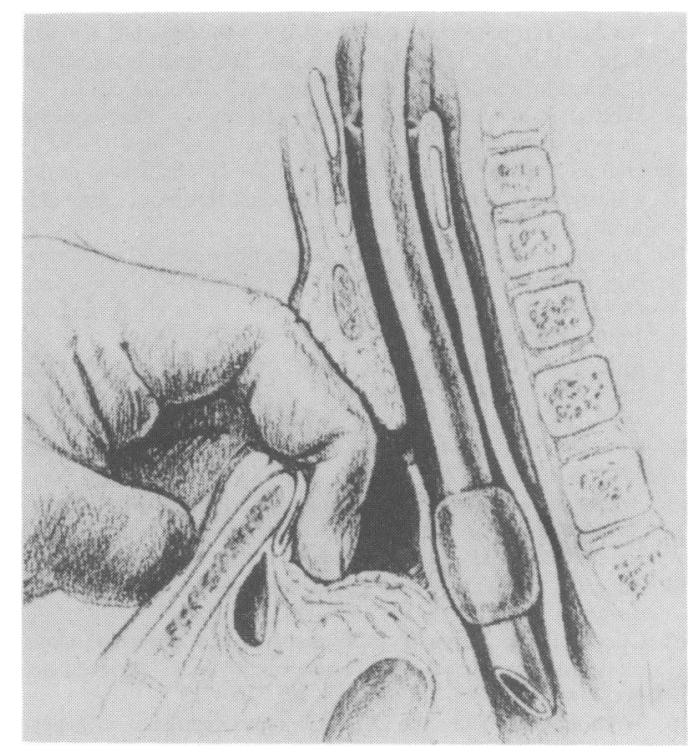

Figure 3 Illustration showing digital compression technique for emergency control of massive haemorrhage due to tracheo-innominate artery fistula. Reproduced with permission from $J A M A$ 220(4), p. 578. Copyright 1972, American Medical Association. 
Sepsis is a constant threat in the Intensive Care Unit. Local infection of the tracheal stoma with a purulent discharge is common in those surgically fashioned, but seems to be less frequent in those created by the percutaneous technique. ${ }^{17}$ Nosocomial pneumonia is a particular risk, which has been shown to be increased by tracheostomy. In a prospective study by El-Naggar et al. ${ }^{40}$ there was an eight-fold difference in the number of organisms isolated from the group treated with early tracheostomy. In addition there was a significant delay in extubating these patients. An alternative interpretation of the data might be that tracheostomy and nosocomial infection occurred more commonly in the more severely ill patients, the association only reflecting the nature of the underlying illness.

In conclusion, intubation is often an essential manoeuvre in the treatment of critical illness. It is associated with significant morbidity and mortality but it is arguable whether this is increased by the early use of tracheostomy. In adults, we recom-

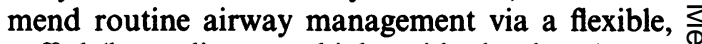
cuffed (large diameter, high residual volume) oro- $\propto$ tracheal tube. Care is needed in minimizing tube mobility and avoiding excessive cuff pressure (greater than $30 \mathrm{mmHg}$ ), to prevent serious laryngotracheal injury. Tracheostomy should generally be reserved for patients requiring prolonged intubation, beyond 10-14 days, where weaning from ventilation is proving difficult. In this situation, percutaneous tracheostomy sited between the first and second tracheal rings, is our method of choice. Cricothyroidostomy and tracheostomy placed below the third ring should be avoided. There is a clear need for more randomized prospective trials, comparing the outcome of switching to tracheostomy in the second week, with persistent transglottic intubation.

\section{References}

1. Alberti, P.W. Tracheotomy versus intubation: A 19th century controversy. Ann Otol Rhinol Laryngol 1984, 93: 333-337.

2. Garrison, F.H. History of Medicine. W.B. Saunders, Philadelphia, 1917, p. 91.

3. Jackson, C. Tracheotomy. Laryngoscope 1909, 19: 285-290.

4. Gunawardana, R.H. Experience with tracheostomy in medical intensive care patients. Postgrad Med J 1992, 68: 338-341.

5. Freeman, G.R. Comparative analysis of endotracheal intubation in neonates, children and adults: complications and treatment. Laryngoscope 1972, 82: 1385.

6. Smith, J.E. \& Grewal, M.S. Cardiovascular effects of nasotracheal intubation. Anaesthesia 1991, 46: 683-686.

7. Blanc, V.F. \& Tremblay, N.A.G. The complications of tracheal intubation. Anaesth Analg 1974, 53: 202-213.

8. Whited, R.E. A prospective study of laryngotracheal sequelae in long-term intubation. Laryngoscope 1984, 94: 367-377.

9. Heffner, J.E., Miller, K.S. \& Sahn, S.A. Tracheostomy in the intensive care unit. Part 1: Indications, technique, management. Chest 1986, 90: 269-274.

10. Toremalm, N.G. Trachea/eosphagus physiology. In: Cummings, C.W. \& Fredrickson, J.M. (eds), Otolaryngology-Head and Neck Surgery, Vol. 3. The C.V. Mosby Company, St Louis, 1986.

11. Bjork, V.O. Partial resection of the only remaining lung with the aid of respirator treatment. $J$ Thorac Cardiovasc Surg 1960, 39: 179-188.

12. Hewlett, A.B. \& Ranger, D. Tracheostomy. Postgrad Med J 1961, 37: 18-21.

13. Bryant, L.R., Mujia, D., Greenberg, S., Huey, J.M., Schechter, F.G. \& Albert, H.M. Evaluation of tracheal incisions for tracheostomy. Am J Surg 1978, 135: 675-679.

14. Toye, F.J. \& Weinstein, J.D. A percutaneous tracheostomy device. Surgery 1969, 65: 384-389.

15. Ciaglia, P., Firsching, R. \& Syniec, C. Elective percutaneous dilatational tracheostomy. A new simple bedside procedure; preliminary report. Chest $1985,87: 715-719$.

16. Toye, F.J. \& Weinstein, J.D. Clinical experience with percutaneous tracheostomy and cricothyroidotomy in 100 patients. J Trauma 1986, 26: 1034-1040.

17. Griggs, W.M., Myburgh, J.A. \& Worthley, L.I.G. A prospective comparison of a percutaneous tracheostomy technique with standard surgical tracheostomy. Intensive Care Med 1991, 17: 261-263.
18. Hazard, P.B., Garrett, H.E., Jr, Adams, J.W., Robbins, E.T. \& Aguillard, R.N. Bedside percutaneous tracheostomy: experience with 55 elective procedures. Ann Thorac Surg 1988, 46: 63-67.

19. Cook, P.D. \& Callanan, V.I. Percutaneous dilational trac@ eostomy technique and experience. Anaesth Intensive Ca⿺ 1989, 17: 456-457.

20. Heffner, J.E. Percutaneous tracheotomy-novel technique o을 technical novelty. Intensive Care Med 1991, 17: 252-253.

21. Jackson, C. High tracheostomy and other errors-the chief cause of chronic laryngeal stenosis. Surg Gynecol Obstet 1921, 32: 392.

22. Brantigan, C.O. \& Grow, J.B., Sr. Cricothyroidotomy: Elective use in respiratory problems requiring tracheotomy. $J$ Thorac Cardiovasc Surg 1976, 71: 72-81.

23. Brantigan, C.O. \& Grow, J.B., Sr. Subglottic stenosis after cricothyroidotomy. Surgery 1982, 91: 217-221.

24. Matthews, H.R. \& Hopkinson, R.B. Treatment of sputum retention by minitracheotomy. Br J Surg 1984, 71: 147-150.

25. Daborn, A.K. \& Harris, M.N. Minitracheotomy: a lifethreatening complication. Anaesthesia 1989, 44: 839-840.

26. Ryan, D.W., Dark, J.H., Misra, U. \& Pridie, A.K. Intraoesophageal placement of minitracheotomy tube. Intensive Care Med 1989, 15: 538-539.

27. Silk, J.M. \& Marsh, A.M. Pneumothorax caused by minitracheotomy [see comments]. Anaesthesia 1989, 44: 663-664.

28. Choudhry, A.K. \& Jackson, I.J. Minitracheotomy: a report of a proposed further development. Ann R Coll Surg Engl 1988, 70: $239-240$.

29. Ryan, D.W. Minitracheotomy [see comments]. $\mathrm{Br}$ Med $J$ 1990, 300: 958-959.

30. Skaggs, J.A. \& Cogbill, C.L. Tracheostomy: management, N mortality, complications. Am Surg 1969, 35: 393-396.

31. Yarington, C.T., Jr \& Frazer, J.P. Complications of tracheotomy. Arch Surg 1965, 91: 652-655.

32. Gaynor, E.B. \& Greenberg, S.B. Untoward sequelae of prolonged intubation. Laryngoscope 1985, 95: 1461-1467.

33. Nordin, U. The trachea and cuff induced tracheal injury. Acta Otolaryngol (Stockh) 1977, 345 (Suppl): 6-34.

34. Lewis, F.R., Jr, Schlobohm, R.M. \& Thomas, A.N. Prevention of complications from prolonged tracheal intubation. Am J Surg 1978, 135: 452-457. 
35. Kuriloff, D.B., Setzen, M., Portnoy, W. \& Gadaleta, D. Laryngotracheal injury following cricothyroidotomy. Laryngoscope 1989, 99: 125-130.

36. Mathog, R.H., Kenan, P.D. \& Hudson, W.R. Delayed massive haemorrhage following tracheostomy. Laryngoscope 1971, 81: 107-119.

37. Bradley, P.J. The obstructed airway. In: Kerr, A.G. (ed.). Scott-Brown's Otolaryngology. Butterworths, London, 1987, pp. $155-168$.

38. Jones, J.W., Reynolds, M., Hewitt, R.L. \& Drapanas, T. Tracheo-innominate artery erosion: successful surgical management of a devastating complication. Ann Surg 1976, 184: 194-204.
39. Utley, J.R., Sìnger, M.M., Roe, B.B., Fraser, D.G. \& Dedo, H.H. Definitive management of innominate artery haemorrhage complicating tracheostomy. JAMA 1972, 220: 577-579.

40. El-Naggar, M., Sadagopan, S., Levine, H., Kantor, H. \& Collins, V.J. Factors influencing choice between tracheostomy and prolonged translaryngeal intubation in acute respiratory failure: a prospective study. Anaesth Analg 1976, 55: $195-201$. 